\title{
Dudak damak yarıklı hastalarda alveoler distraksiyon osteogenez uygulamaları: literatür derlemesi
}

\author{
Öznur Mülayim, Fatma Deniz Uzuner, \\ Belma Işık Aslan \\ Ortodonti Anabilim Dalı, Gazi Üniversitesi Diş Hekimliği \\ Fakültesi, Ankara, Türkiye
}

\begin{abstract}
ÖZET
Kraniyofasiyal bölgede başarıyla uygulanmakta olan distraksiyon osteogenezis yönteminin dudak damak yarıkı bireylerde uygulanmasının giderek artığı görülmektedir. Özellikle geniş damak yarıklı hastalarda düzgün bir alveolar ark sağlanmasına yönelik olarak kemik greftleme veya distraksiyon osteogenezis gibi cerrahi işlemler uygulanabilmektedir. Bu derlemede dudak damak yarığı olan bireylerde alveolar (segmental) distraksiyon osteogenezis uygulayan çalışmaların verileri ışığında, uygulamanın endikasyonları, avantaj ve dezavantajları, uygulama metodları ve bu amaçla kullanılan aparey çeşitleri değerlendirildi. Sonuç olarak, özellikle alveolar distraksiyon osteogenezis uygulaması ile velofaringeal yetmezlik, maksiller hipoplazi ve maksiller çapraşıklığa sahip dudak damak yarı̆̆ı olan hastalarda başarılı sonuçlar elde edilebildiği ve buyöntemin konvansiyonel osteotomilere ve ağız dışı distraktörlerle yapılan distraksiyon uygulamalarına alternatif olabileceği belirlendi.
\end{abstract}

Anahtar Kelimeler: Distraksiyon osteogenezis; ortodonti; yarık damak; yarık dudak

KaYNAK GöstermeK İçiN: Mülayim Ö, Uzuner FD, Işık Aslan B. Dudak damak yarıklı hastalarda alveoler distraksiyon osteogenez uygulamaları: literatür derlemesi. Acta Odontol Turc 2016;33(2):102-8

EрітöR: Nilüfer Darendeliler, Gazi Üniversitesi, Ankara, Türkiye

YAYıN HAKKI: @ 2016 Mülayim ve ark. Bu eserin yayın hakkı Creative Commons Attribution License ile ruhsatlandırımıştır. Sınırsız kullanım, dağıtım ve her türlü ortamda çoğaltım, yazarlar ve kaynağın belirtilmesi kaydıyla serbesttir.

[Abstract in English is at the end of the manuscript]

Makale gönderiliş tarihi: 28 Mayıs 2015; Yayına kabul tarihi: 20 Ağustos 2015 *iletişim: Fatma Deniz Uzuner, Gazi Üniversitesi Diş Hekimliği Fakültesi Ortodonti Anabilim Dalı, 06510, Emek, Ankara, Türkiye;

E-posta: fduzuner@yahoo.com.tr
Giriş

Dudak damak yarıkları (DDY), kraniyofasiyal bölgenin konjenital anomalileri arasında en yaygın gözlenen malformasyonlardandır. DDY, sadece bölgedeki yumuşak ve sert dokuların devamlılığını bozmakla kalmayıp aynı zamanda orta yüz bölgesinin büyüme ve gelişim bozukluğu ile sonuçlanacak fonksiyonel düzensizliklere de neden olmaktadır.

Yarık dudak ve/veya damağın cerrahi olarak kapatılmasının sonrasında büyüme ve gelişim ile birlikte dişsel ve iskeletsel yapılarda gelişen malokluzyonun düzeltilmesinde ortodontik tedaviler tek başına yeterli olmamakta, beraberinde cerrahi uygulamaların desteğine de intiyaç duyulabilmektedir. ${ }^{2}$

Özellikle geniş damak yarıkı hastalarda düzgün bir alveolar ark sağlanmasına yönelik olarak kemik greftleme yöntemi veya distraksiyon osteogenezis (DO) gibi cerrahi ișlemler uygulanabilmektedir. ${ }^{2} \mathrm{Bu}$ hastalarda kemik greftleme yöntemi de tek başına yeterli olamayabilmektedir. Başarısızlıkta en büyük etken; yeterli yapışık dişeti desteği ile yarığın kapatılamaması ve/veya çok fazla miktarda kemik grefti uygulanması gerekliliğidir. ${ }^{3,4}$ Kemik grefti kullanılacak hastalarda önce alveolar (segmental) DO uygulanmasının avantaj oluşturduğu belirtilmektedir..$^{3-5}$ Alveolar DO'nun geniş alveolar yarık (maksiller kanin diş genişliğinden daha fazla), oronazal fistül veya maksiller defektlerin tedavisinde kullanımı bildirilmektedir. Geniş alveol yarığına sahip hastalarda alveolar DO uygulanarak alveol yarığın kapandığı veya genişliğin azaltıldığı ve ortodontik tedavinin de daha kolay hale geldiği belirtilmektedir. ${ }^{3-5}$

Bu derlemenin amacı, bu spesifik hasta grubunda uygulanabilecek alternatif tedavi metodlarından biri olarak alveolar DO uygulamalarını yapılan çalışmaların ışığında değerlendirmek; DO histogenezisini, uygulamanın endikasyonlarını, avantaj ve dezavantajlarını, uygulama metodlarını, bu amaçla kullanılan aparey çeşitlerini ve bu apareylerin avantaj ve dezavantajlarını belirlemektir. 


\section{Distraksiyon osteogenezis histogenezi}

DO ile kademeli olarak birbirinden uzaklaştırılan kemik segmentlerinin yüzeyleri arasında yeni kemik oluşumu sağlanabilmektedir. ${ }^{6}$ Distraksiyon kuvveti, kemik segmentleri birleştiren dokularda gerilim meydana getirmekte ve distraksiyon vektörüne paralel yeni kemik oluşumunu uyarmaktadır. ${ }^{7,8}$

Distraksiyon sırasında kemiğe uygulanan distraksiyon kuvvetleri ile çevre dokularda değişimler meydana gelmektedir. Distraksiyon histogenezi olarak adlandırılan ve birbirini takip eden bu adaptif değişimler mukoza, dişeti, periodontal ligament, periost, sinir, kan damarları, kıkırdak, fasia, kaslar, deri gibi çevre dokularda da gerilime neden olmaktadır. Yumuşak dokudaki bu adaptif değişimler DO ile geniş iskeletsel harekete izin verirken relaps oluşumunu da azaltmaktadır. ${ }^{6,9,10}$

Distraksiyon işleminde farklı biyolojik olayların gerçekleştiği birbirini takip eden 3 ana faz bulunmaktadır. ${ }^{11}$

1. Latent faz: Osteotominin yapılmasından traksiyonun başlamasına kadar geçen dönemdir. Bu dönemde yumuşak kallus oluşmaktadır. Klinik alveoler distraksiyonda kemiğin prematür ekspozurunu engellemek için 4-7 günlük latent süre endikedir.

2. Distraksiyon fazı: Transfer edilen kemik segmentine gerilme kuvvetinin uygulandığı ve yeni immatur dokunun oluştuğu dönemdir. İdeal miktar günde $1 \mathrm{~mm}$ dir. Alveoler distraksiyonda bu dönem genelde 1-2 haftada sonlanır.

3. Konsolidasyon fazı: Yeni oluşmuş kemiğin maturasyonuna müsaade edilen dönemdir. Teorik olarak, distraksiyon sahasında yeni oluşmuş kemik içerisine hızlı diş hareketini başlatmak için kemik formasyonunun henüz başlamadığı yani kemik rezistansının en az olduğu dönem en uygunudur. Ancak cerrahi sonrasında gelişen geçici, baskın osteoklastik aktiviteye bağlı olarak kortikal kemikte incelme ve periodontal ligamentte genişleme gözlenmektedir.6,12 Bazı çalışmalar distraksiyon sonrası erken dönemde diş hareketinin yapılabileceğini gösterirken, ${ }^{12-14}$ diğerleri 8-12 haftalık bir konsolidasyon süresinin beklenmesi gerektiğini vurgulamaktadırlar. ${ }^{15-17}$

\section{Uygulama yöntemi}

İdeal alveolar distraksiyon sahasının özellikleri şu şekilde tanımlanmaktadır: $:^{3,18}$

1. Distraksiyon sahası, cerrahi sonrası primer kapatmaya olanak sağlayacak yeterli ve sağlıklı yapışık dişeti ve oral mukoza intiva etmelidir.

2. Distraksiyon sahasındaki interseptal kemik kalınlığı, en az $3 \mathrm{~mm}$ ve mümkün olduğunca fazla olmalıdır. Distraksiyon sahasının her iki yanında en az 1 mm'lik alveoler kemik korunmalıdır. Interdental kemik genişliğinin en geniş olduğu alan 1. büyükazı ve ikinci küçükazı dişlerin arası olarak bildirilmektedir.
3. Oral mukoza veya yapışık dişetinden kan desteği sağlayabilmek için distrakte edilen segment en az 2 diş içermelidir.

Alveolar yarığın distalinde dental arkta interdental osteotomi yapılır. Üst çenede mukoperiosteal flap kaldırımasını takiben bukkal ve palatalinalden dişlerin arasından vertikal kesiler ve bu kesileri birleştiren horizontal kesi yapılır. Segment serbestleştirilir, distraksiyon aygıtı yerleştirilir. Kaldırılan flabin kesi bölgesinde düzgün ve dikkatli bir şekilde kapatılması distraksiyon esnasında yumuşak doku yırtımasının oluşmaması açısından önemlidir. Yumuşak dokudaki yırtılma yumuşak kallus dokusunun açığa çıkmasına ve ciddi kemik erimelerine, dişeti çekilmesi ve diş kökünün açığa çıkmasına neden olabilecektir. Bu nedenle yumuşak doku iyileşmesinin sağlandığı 3-7 günlük latent dönem sonrası distraksiyona başlanması uygun görülmektedir. Günlük ortalama 1 $\mathrm{mm}$ aktivasyon önerilmektedir. Aktivasyon, alveolar yarığın kapanmasına kadar sürer. ${ }^{3,18}$ Tam bir görüş birliği bulunmamakla birlikte, distraksiyon ile edilen yeni kemiğe doğru 1-12 hafta sonra ortodontik diş hareketlerine başlanması önerilmektedir. ${ }^{19,20}$ Liou ve ark. $^{3}$ ise yeni oluşan kemiğin olgulaşması sırasında büzülmesini önlemek amacıyla mümkün olan en kısa sürede diş hareketini önermektedir. Bununla beraber erken dönemde ortodontik diş hareketine başlandığında ise kök rezorpsiyonu riski göz önünde bulundurulmalıdır. ${ }^{18} \mathrm{H} ı$ zlı diş hareketinin yapıldığı ilk 2 ayda hastalar haftalık periyodda kontrole çağrılırken daha sonra aylık kontrollere çağrılır.3,12,18

\section{Avantaj ve dezavantajları}

DDY'li hastalarda alveolar DO uygulamasının avantajları özetle:3,18,21,22

1. Geniş alveoler yarıklar daraltılabilir. Dar alveolar yarıklar ise kemik greftleme ve/veya ilave gingivoperiosteoplastiye intiyaç duyulmadan tamamen kapatılabilmektedir.

2. Maksiller arkta uzun dönem stabilizasyon sağlanır.

3. Maksiller deformitelerle birlikte geniş deviasyonlar, iyi maksiller ark formu sağlayarak düzeltilebilir.

4. Kemik grefti uygulandığında greft hatasız şekilde yerleştirilir ve daha uzun dayanır.

5. Obtüratörlü dental protezlere ihtiyaç azalır.

6. Oronazal fistül olasılığı azalır/ortadan kalkar ve oluşan kemik dişin sürmesine de izin verebilir.

7. Kemik ve yumuşak doku greftine olan intiyaç azalır ve böylece donör saha morbiditesi oluşmaz.

8. Dental arkta yeni alveolar kemik oluşumu ile çapraşıklıklar diş çekimi gerektirmeden ortodontik tedavi ile hızla düzeltilebilmektedir. Maksiller arkta şiddetli çapraşıklığı bulunan ve maksillaya total sagital DO veya ortognatik cerrahi uygulanan hastalarda maksillada yer kazanılamamakta ve yer kazanmak 
amacıyla premolar diş çekimine intiyaç duyulmaktadır. ${ }^{23-}$ ${ }^{25}$ Buna karşılık, alveolar DO ile ark uzunluğunda artış sağlanabilmekte, yarık kapatılabilirken ayrıca yeni kemik oluşumu sağlanarak dental arktaki çapraşıklığın düzeltilmesinde diş çekimi gerektirmeyecek şekilde yer sağlanabilmektedir.

9. Hızlı ortodontik diş hareketleri sağlanabilmektedir. Elde edilen düzelme daha stabil olmakta, relaps az gözlenmektedir.

10. Yumuşak damak distraksiyon süresince ve sonrasında yerinde korunmaktadır, böylece velofaringeal fonksiyonlar korunmakta, yetmezlik gelişmemektedir. Le Fort I maksiller ilerletme veya total sagittal DO uygulamaları ile üst çene ile birlikte velofarengeal dokular da öne taşınmaktadır ve velofarengeal yetmezlik gelişebilmektedir. ${ }^{26,27}$ "Velofarengeal kapanması" iyi olan DDY'li hastalar her zaman bu durumdan etkilenmese de özellikle velofarengeal kapanması sınırda veya riskli olan hastalarda durumun daha da kötüleşmesi intimali vardır. ${ }^{26}$ Gelişen velofaringeal yetmezliğin ilave cerrahi yöntemlerle kapatılması gerekebilmektedir. ${ }^{28}$ Diğer taraftan, alveoler DO tekniğinde ise; posterior maksiller bölgedeki kemik ve yumuşak dokular yerinde kalmakta, birinci molar dişin hemen önünden ilerletme yapılabilmekte, böylece velofaringeal dokular etkilenmemektedir. ${ }^{24,26,29}$

11. Çift taraflı damak yarıkı bireylerde uygulanabilir. Sağ vesol tarafta farklı segmental hareketler sağlanabilmekte böylece hem alveolar yarık kapatılabilirken hem de maksillanın öne doğru ilerletilebilmesi sağlanabilmekte; maksiller yetmezlik ve velofaringeal yapı bozulmadan düzeltilebilmektedir. Buna karşılık çok şiddetli maksiller yetmezlik vakalarında ağız içi distraktörlerin kısıtlı aktivasyonuna bağlı olarak alveolar distraksiyon yetersiz kalabilmektedir ki bu vakalarda ağız dışı distraktör kullanımına intiyaç duyulabilmektedir. Özellikle orta yüz bölgesinde şiddetli gelişim geriliği mevcut olan DDY'li bireylerde maksiller ilerletme amacıyla Polley ve Figueroa'nın ${ }^{30,31}$ geliştirmiş oldukları Rijit Eksternal Distraksiyon (RED; KLS-Martin LP) apareyi etkin bir yöntem olarak kullanılmaktadır.

DDY'li bireylerde uygulanan alveolar DO, uzun kemiklerde ${ }^{7,8}$ veya kraniofasiyal bölgede $e^{9,32-34}$ uygulanan DO'ya prensipte benzemekle beraber klinik durum farklılık göstermektedir. Alveolar yarığı, oronazal fistülü olan bu bireylerde oluşturulan kemik segmentler oral ve/veya nazal kavitelere açılmaktadır. Bu nedenle alveolar segmentlerin mümkün olduğunca biraraya getirilmesi arzu edilmektedir. Yeterli olmadığında distraksiyon tamamlansa da kemik greftine veya gingivoperiosteoplastiye intiyaç duyulabilmektedir. ${ }^{3}$

DO uygulamasının dezavantajları ise: ${ }^{35,36}$

1. Distraksiyon yönünün yanlış belirlenmesi ile istenen yönde ve miktarda distraksiyon sağlanamaması,

2. Hareket ettirilen segmentin kırılması, üzerindeki mukozanın yırtılması,

3. Dikişlerin açılması,
4. Distraksiyon sonrasında kemik oluşumunda bozukluk gelişmesi olarak özetlenebilir.

Gerekli önlemlerin alınması, doğru aygıt şeçimi ve tekniğin doğru kullanımı ile bu komplikasyonlar önlenebilecektir.

\section{Alveolar distraksiyon osteogenezisinde kullanılan aygitlar}

Alveolar DO'da ağız içi veya ağız dışı distraktörler kullanılabilmektedir. ${ }^{19,22}$ Ağız dışından uygulamada RED aygıtı kullanılmaktadır. ${ }^{22}$ RED aygıtı kullanımının ciltte skar bırakması ve hastalar tarafından sosyal olarak kolay kabul edilmemesinden dolayı ağız içi distraktörler daha sıklıkla tercih edilmektedir. Ağız içi distraktörler aynı zamanda daha tolere edilebilir olduklarından, ağızda konsolidasyon dönemi boyunca daha uzun sure retansiyonu sağlanabilmektedir. ${ }^{24,37,38-}$ 40 Ancak ağız içi distraktörlerle distraksiyon miktarı ve kuvvetlerin üç boyuttaki kontrolu daha sınırlı olmaktadır. ${ }^{40} \mathrm{Bu}$ distraktörler, bukkalden ${ }^{3,4,40}$ veya palatinalden $24,29,38$ uygulanabilmektedir. Bukkal uygulamalarda distraktörlerin birbirine ve distraksiyon vektörüne paralel olarak konumlandırılması gerekliliği uygulama güçlüğü yaratabilmektedir. ${ }^{40}$

Alveolar DO'da kullanılan ağıziçi aygıtlar destek aldıkları bölgeye göre 3 gruba ayrılmaktadır., Bunlar:

1. Kemik destekli distraktör (sadece kemikten destek alan)

2. Diş destekli distraktör (sadece dişten destek alan)

3. Hibrid distraktör (hem kemik hem de dişten destek alan)

\section{Kemik destekli ağız içi distraktörler}

$\mathrm{Bu}$ tip distraktörlerde desteğin tamamı distraksiyon bölgesine komşu kemiğe vidaların yerleştirilmesi ile sağlanmaktadır.Yerleştirilmeleri diş destekli olanlara göre daha zordur ${ }^{18,41}$

Kemik destekli distraktör kullanıldığında distraksiyon, düz bir hat üzerinde gerçekleştiği için simetrik ve ovoid bir ark formu yaratabilmek amacıyla ikincil bir ortodontik tedaviye intiyaç duyulmaktadır. ${ }^{42}$ Aynı zamanda bu distraktör tipi kullanıldığında osteotomize edilmiş (serbestleştirilmiş olan) olan kemik bölümünün üst kısmı okluzal seviyeye göre daha fazla distrakte edilmektedir. Bu sebeple distraksiyon vida sistemine ilave olarak okluzal seviyede de ark teline ağır nikel titanium yayların ilave edilmesiyle kütlesel bir distraksiyon sağlanabilmekte ve uygun bir alveolar ark şekli elde edilebilmektedir. Ortodontik ark teli kesilen segmentin distraksiyon sırasında medial ve palatinale doğru kollabe olmasını da engellemektedir. ${ }^{18}$

Kemik destekli distraktörlerin çıkarılması için ikinci bir ameliyata intiyaç duyulması en önemli dezavantajıdır. ${ }^{42}$ 


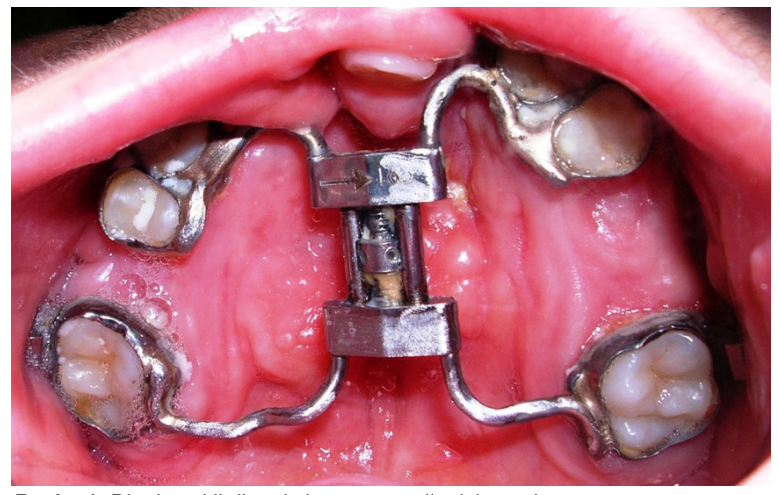

Resim 1. Diş destekli distraksiyon aygıtı ağız içi uygulanımı

\section{Diş destekli ağız içi distraktörler}

Kişiye özel olarak hazırlanan bu tip distraktörlerde destek dişlere çelik kuron veya ortodontik bant yerleştirilmekte, distraktör vidası laboratuarda bu parçalara lehimlenmektedir (Resim 1). ${ }^{21} \mathrm{Bu}$ amaçla hyrax tipi ortodontik vidalar kullanılabilmektedir. ${ }^{24,29,38}$

Kemik destekli olanlara göre diş destekli distraktörlerin daha fazlasıyla destek aldığı dişleri hareket ettirdiği belirtilmektedir. ${ }^{23}$ Farklı olarak Liou ve ark. $^{3}$ ise çalışmalarında destek dişlerden ziyade kemik segmentin hareket ettirildiğini bildirmektedirler.

Diş destekli distraktörlerin çıkarılması için ikinci bir invaziv girişime (ameliyat) intiyaç duyulmaması ise en önemli avantajıdır. ${ }^{18,37}$

\section{Hibrid ağız içi distraktörler}

Desteğin bir kısmını distraksiyon bölgesine komşu kemiğe vidalar ile sabitlenerek, bir kısmını da distraktör kolları dişlere kuron veya bant yardımı ile sabitlenerek alan distraktör tipidir (Resim 2). ${ }^{43}$ Bukkalden uygulanan hybrid distraktörler ile maksiller segmentte rotasyonel hareket sağlanabilmektedir. ${ }^{40}$

\section{Maksiller alveoler (segmental) sagital distraksiyon osteogenezis uygulamaları}

Alveolar DO 1990'da ilk Constantino ve ark. ${ }^{44}$ tarafından köpek mandibulasında denenmiş ve başarılı sonuçlar bildirilmiştir. Daha sonra 1994 yılında Block ve Brister'in çalışmasında ${ }^{45} 3$ köpekte interdental osteotomi hattı ikinci lateral ile köpek dişi arasından geçirilmiş ve alveolar DO gerçekleştirilmiştir. Araştırıcılar çalışmalarının sonucunda distraksiyon aralığı boyunca yumuşak doku defekti oluşmaksızın tam bir iyileşme sağlandığını belirtmişlerdir. ${ }^{45}$

İlerleyen yıllar içinde DDY'li bireylerde de farklı ağız içi aygıt ve mekaniklerin kullanıldığı alveolar DO uygulamaları rapor edilmiştir. 3,18,24,29,41,46,47

Liou ve ark. ${ }^{3} 2000$ yılındaki çalışmalarında, alveolar yarığı minimize etmek için özel yapım intraoral, diş destekli bir distaksiyon apareyi ile kuvvetleri osteotomize dental arka dağıtmışlardır. Yen ve ark. ${ }^{46} 2001$ yılında, konvansiyonel sabit ortodontik tedavide kullanılan braket, ark teli ve yaylar ile lingual aygıtlardan yapılmış diş ve kemik destekli bir distraktörle 8 oz'luk (226.8 g) kuvvet tatbik ederek, 22 mm'lik geniş bir unilateral yarık tedavi etmişlerdir. Bu yazarlar, ark şekilli bir aparey hazırladıklarından ya da distraksiyon periyodu süresince apareye bükümler verdiklerinden dolayı hareketin üç boyutlu kontrolünü sağladıklarını vurgulamışlardır.

Bazı araştırmacılar da Hyrax tipi diş destekli aparey dizaynı ile başarılı DO uygulamaları bildirmişılerdir. ${ }^{24,29,47}$ Tae ve ark. ${ }^{47}$ unilateral DDY'li 20 yaşındaki kadın hastada, hyrax tipi diş destekli distraksiyon apareyini üst birici küçükazı ve birinci büyükazı arasına yerleştirmişler ve alveolar DO uygulamışlardır. Yazarlar, prosedürü uygularken herhangi bir komplikasyonla karşılaşmadan yeni oluşturulmuş kemik içerisine doğru hızlı diş hareketi elde edebildiklerini rapor etmişlerdir.

Karakasis ve Hadjipetrou da çalışmalarında ${ }^{41}$ interdental osteotomi hattının 2. premolar dişlerin distalinden geçirilerek, kemik destekli distraktör (Zürih Pediatric Ramus Distraktörü, KLS Martin, Tuttlingen, Almanya) ile maksillada posterior alveolar sagital distraksiyon osteogenezi gerçekleştirmişlerdir. DDY olan bu hastada kullanılan DO yönteminin velofaringeal fonksiyonu etkilemeden uygulanabildiği belirtilmiştir.

Liou ve Chen ${ }^{18} 2009$ yılında bir maksiller kanin diş genişliğinden daha büyük alveolar yarığa sahip 21 hastayla yaptıkları çalışmada alveolar DO ve alveolar greftleme uygulamışlar ve 13 vakada da ankraj için minividalar kullanarak bukkal dişlerin ortodontik protraksiyonunu sağlamışlardır. Bu vakalarda dişlerin hareketi, aralıklı (intermittent) hafif kuvvetlerle sağlanmıştır. Araştırmacılar, sonuçların stabil kaldığını

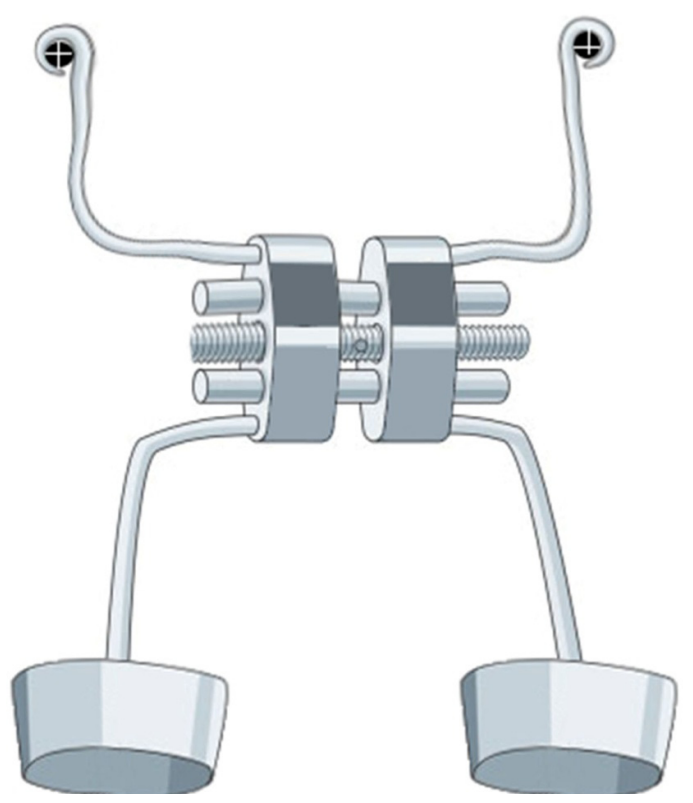

Resim 2. Hibrid distraksiyon aygıtı. Yukarıda vidalar ile kemiğe tutturulan kısım ve aşağıda destek alınacak dişler için hazırlanmış olan bantlara lehimlenen kısımdan oluşmaktadır. 
bildirmişlerdir.

Vega ve ark. ${ }^{43}$, Hyrax apareyini modifiye ederek hibrid tipi VEGAX apereyini geliştirmişlerdir. Bukkal bölgeden uygulanan aparey ile 5'i DDY'li toplam 8 hastada başarılı bir şekilde alveolar kemiğin transportasyonunun sağlandığı rapor edilmiştir.

Erverdi ve ark. ${ }^{37} 2012$ yılında alveolar yarık onarımı için ark boyunca alveolar DO yöntemini (AWDA) tanıtmışlardır. Bu yöntem, 019×25 çelik ark teline yerleştirilen Erverdi (Tasarım Med, Istanbul, Turkey) tarafından tasarlanmış olan diş destekli bir distraktör ile uygulanmıştır. $12-13$ ve 25-26 no'lu dişler arasına yerleştirilen iki adet distraktör alveolar segmentler birbirine temas edinceye kadar günde 2 kez aktive edilmiştir. Distraktörün, kolay uygulanma, aktivasyon ve ikinci bir operasyona gerek kalmadan çıkarılabilme avantajları belirtilmiştir. Bu yöntemin en büyük avantajı ise; rijit ark teli rehberliğinde distraksiyonla elde edilen küçük linear kemik segmentlerin ark formunda eğim alması sağlanarakideal birarkformununelde edilmesidir. Ancak dişlerin önlenemeyen eğilme hareketinden dolayı yarık alanının tamamen kapatılamadığı bildirilmiştir.

Erverdi ve arkadaşları daha sonraki çalışmasında dişlerde oluşan eğilmeleri daha iyi kontrol altında tutmak amacıyla daha rijit bir sistem geliştirmişlerdir. ${ }^{48}$ Premaksillası olmayan bilateral DDY hastasında, premaksillanın rekonstrüksiyonu ve sagital çene ilişkisinin düzeltimi amacıyla yeni bir metod sunmuşlardır. İkinci küçükazı ve birinci büyükazı dişler arasından vertikal insizyonlar ve diş köklerinin üzerinden seyreden horizontal osteotomiler yapılarak ark ve distraktörler intraoperatif olarak yerleştirilmiştir. Ortalama \%30 oranında aşırı düzeltim sağlanacak şekilde aktivasyon yapılmıştır. Araştırıcıların diğer vaka raporunda da tek taraflı DDY hastasında metal kronlar ile kaplanmış olan dişlere 1.5 mm'lik çelik ark lehimlenmiş ve ağız içi distraktör bu çelik arka yerleştirildikten sonra cerrahi olarak serbestleştirilmiş olan segmentler bu ark rehberliğinde hareket ettirilmiştir. ${ }^{49} \mathrm{Bu}$ kontollü vektör metodu (vector-controlled method) ile yeni kemik yapımının ve yapışık dişeti formasyonunu sağladığı, uygun bir alveolar ark şeklinin elde edilebildiğini bildirmişlerdir. ${ }^{48,49}$

Sunitha ve ark. ${ }^{38}$ ise $15-25$ yaşları arasındaki 8 DDY hastasında yaptıkları bir çalışmada, premolar bölgesinden yapılan interdental vertikal osteotomiler ve palatinalden Hyrax vidası içeren diş destekli bir distraktör ile anterior maksiller distraksiyon osteogenezi gerçekleştirmişlerdir. Yazarlar, uygulama sonrası maksillanın anterior ve superior hareketini, mandibuler düzlem açısında ve alt yüz yüsekliğinde artışı, ayrıca maksiller anterior ve posterior segmentlerin ekstrüzyonunu gözlemlemişlerdir.

Bousdras ve ark. ${ }^{39} 2014$ yılında geniş bir alveolar yarığın onarımı için, alveolar segmentin maksiller ark kurvatürüne doğru hareketine izin veren farklı özel yapım bir diş desteki distraktör imal etmişlerdir. Palatinalden asimetrik uygulanan bir Hyrax vidası kullanılmştır.
Apareyin özellikle unilateral yarıklarda uygulanabilir olmasını sağlayan farkılığını, distrakte edilmeyen maksiller segment üzerinde rijit bir kol içermesi olarak açıklamışlardır.

Yapılan çalışmalar değerlendirildiğinde; alveoler distraksiyon osteogenezinin, geçmişten günümüze dudak damak yarıklı bireyler için sunulmuş tedavi protokolleri arasında fiziksel, sosyal ve ekonomik açıdan en az travmatik olan yöntemler arasında olduğu söylenebilir.

\section{SONUÇ}

Alveolar DO uygulaması ile velofaringeal yetmezlik, maksiller hipoplazi ve maksiller çapraşıklığa sahip DDY olan hastalarda başarılı sonuçlar elde edilebilmektedir. Dental arkta yeni yerler kazanılmakta, velofarengeal yetmezliğin artması veya oluşması engellenmekte, yarık alanlarının kapatılması için gerekli olan greft intiyacı da azalmaktadır. Alveolar distraksiyon osteogenezi yeni gelişmekte olan bir tekniktir, kraniomaksillofasiyal cerrahide yaygın olarak kullanılabilmesi için modifikasyonların ve yeni uygulamaların geliştirilmesine intiyaç duyulmaktadır.

\section{TEŞEKKÜR VE ANMA}

Derlemenin hazırlanmasında fotoğraf desteğinde bulunan Doç. Dr. Ayşe Gülşen'e teşekkür ederiz.

Çıkar çatışması: Yazarlar bu makale ile ilgili herhangi bir çıkar çatışmalarının ulunmadığını bildirmişılerdir.

\section{KAYNAKLAR}

1. Bıçakçı $A A$, Nalçacı $R$, Turgut M. Damak dudak yarıklı bir hastada multidisipliner tedavi yaklaşımı (Olgu sunumu). Türk Diş Hek Derg 2007;69:136-8.

2. Fonseca RJ, Marciani RD, Turvey TA. Oral and Maxillofacial Surgery. 2nd edn. Philadelphia: Elsevier; 2008. p. 528.

3. Liou EJ, Chen PK, Huang CS, Chen YR. Interdental distraction osteogenesis and rapid orthodontic tooth movement: a novel approach to approximate a wide alveolar cleft or bony defect. Plast Reconstr Surg 2000;105:1262-72.

4. Dolanmaz D, Karaman Al, Durmuş E, Malkoç S. Management of alveolar clefts using dentoosseous transport distraction osteogenesis. Angle Orthod 2003;73:723-9.

5. Binger T, Katsaros C, Rucker M, Spitzer WJ. Segment distraction to reduce a wide alveolar cleft before alveolar bone grafting. Cleft Palate Craniofac J 2003;40:561-5.

6. Samchukov ML, Cope JB, Cherkasin AM. Craniofacial Distraction Osteogenesis. 1st edn. St Louis: Mosby; 2001.

7. Ilizarov GA. The tension-stress effect on the genesis and growth of tissues. Part I. The influence of stability of fixation and soft- tissue preservation. Clin Orthop Relat Res 1989;249-81.

8. llizarov GA. The tension-stress effect on the genesis and growth of tissues: Part II. The influence of the rate and frequency of distraction. Clin Orthop Relat Res 1989;263-85.

9. Block MS, Daire J, Stover J, Matthews M. Changes in the inferior alveolar nerve following mandibular lengthening in the dog using distraction osteogenesis. J Oral Maxillofac Surg 1993;51:652-60.

10. Yasui N, Kojimoto $H$, Shimizu $H$, Shimomura $Y$. The effect of distraction upon bone, muscle, and periosteum. Orthop Clin North Am 1991;22:563-7.

11. Cano J, Campo J, Moreno LA, Bascones A. Osteogenic alveolar distraction: A review of the literature. Oral Surg Oral Med Oral Pathol 
Oral Radiol Endod 2006;101:11-28.

12. Liou EJ, Figueroa AA, Polley JW. Rapid orthodontic tooth movement into newly distracted bone after mandibular distraction osteogenesis in a canine model. Am J Orthod Dentofac Orthop 2000; 117:391-8.

13. Duran I, Malkoc S, Iseri H, Tunali M, Tosun M, Kucukkolbasi $\mathrm{H}$. Microscopic evaluation of mandibular symphyseal distraction osteogenesis. Angle Orthod 2006;76:369-74.

14. Malkoc S, Iseri H, Karaman Al, Mutlu N, Kucukkolbasi H. Effects of mandibular symphyseal distraction osteogenesis on mandibular structures. Am J Orthod Dentofacial Orthop 2006;130:603-11.

15. Cope JB, Samchukov ML. Regenerate bone formation and remodeling during mandibular osteodistraction. Angle Orthod 2000;70:99-111.

16. Nakamoto N, Nagasaka H, Daimaruya T, Takahashi I, Sugawara J, Mitani $\mathrm{H}$. Experimental tooth movement through mature and immature bone regenerates after distraction osteogenesis in dogs. Am J Orthod Dentofacial Orthop 2002;121:385-95.

17. El Sharaby FA, El Bokle NN, El Boghdadi DM, Mostafa YA. Tooth movement into distraction regenerate: When should we start? Am J Orthod Dentofacial Orthop 2011;139:482-94.

18. Liou JW, Chen KT. Intraoral Distraction of Segmental Osteotomies and Miniscrews in Management of Alveolar Cleft. Semin Orthod 2009;15:257-67.

19. Nakamoto N, Nagasaka H, Daimaruya T, Takahashi I, Sugawara J, Mitani $\mathrm{H}$. : Experimental tooth movement through mature and immature bone regenerates after distraction osteogenesis in dogs. Am J Orthod Dentofac Orthop 2002;121:385-95.

20. Cope JB, Harper RP, Samchukov ML. Experimental tooth movement through regenerate alveolar bone: a pilot study. Am J Orthod Dentofac Orthop 1999;116:501-5.

21. Richardson S, Agni NA, Selvaraj D. Anterior maxillary distraction using a tooth borne device for hypoplastic cleft maxillas - a pilot study. J Oral Maxillofac Surg 2011;69:542-8.

22. Wang $X X$, Wang $X$, Li ZL, Yi B, Liang $C$, Jia YL et al. Anterior maxillary segmental distraction for correction of maxillry hypoplasia and dental crowding in cleft palate patients: a preliminary report. Int J Oral Maxillofac Surg 2009; 38:1237-43.

23. Posnick, JC, Tompson B. Cleft-orthognathic surgery: Complications and long-term results. Plast. Reconstr. Surg. 1995;96:255-66.

24. Alkan A, Baş B, Özer $M$, Bayram M, Yüzbaşıŏlu E. Maxillary anterior segmental advancement of hypoplastic maxilla in cleft patients by distraction osteogenesis: report of 2 cases. J Oral Maxillofac Surg 2008;66:126-32.

25. Van Sickels JE. Distraction osteogenesis versus orthognathic surgery. Am J Orthod Dentofacial Orthop 2000;118:482-4.

26. Nalcacı R, Topbaş S, Orhan M, Doruk C. Importance of speech disorders in cleft lip and palate patients, assessment of speech therapy and evaluation of distraction osteogenesis: Two case reports. Turkish Journal of Orthodontics 2009;22:45-53.

27. Guyette TW, Polley JW, Figueroa A, Smith BE. Changes in speech following maxillary distraction. Cleft Palate Craniofac J 2001;38:199205.

28. Ertaş Ü, Saruhan N, Demirci T. Çocuklarda Primer Damak Yarığı Onarımı Sonrası Görülen Velofaringeal Yetmezlik Tedavisi. Atatürk Üniv Diş Hek Fak Derg 2014:9;142-5.

29. Gunaseelan R, Cheung LK, Krishnaswamy R, Veerabahu M. Anterior maxillary distraction by tooth-borne palatal distractor. J Oral Maxillofac Surg 2007;65:1044-9.

30. Polley JW, Figueroa AA. Rigid external distraction: its application in cleft maxillary deformities. Plast Reconstr Surg 1998;102:1360-72.

31. Figueroa AA, Polley JW, Ko EW. Maxillary distraction for the management of cleft maxillary hypoplasia with a rigid externel distraction system. Semin Orthod. 1999;5:46-51.

32. Onur ÖD, Cura N, Erpardo Y. Maksillofasiyal bölgede distraksiyon osteogenezi. iÜ Diş Hek Fak Derg 2004;38:19-24.

33. Karabekmez FE, Irgın C, Sağlam İ, Görgü M. Yüz bölgesi distraksiyon osteogenezis uygulamaları. Abant Med J 2012;1:1-7

34. Keçeli HG, Demiralp B, Muhtaroğulları M, Demiralp $B$.
Dişhekimliğinde Distraksiyon Osteogenez: Bölüm 2. Hacettepe Diş Hek Fak Dergisi 2006;30:20-30.

35. Yang L, Suzuki EY, Suzuki B. Alveolar distraction osteogenesis: a systematic literature review M Dent J 2014; 34,289-300.

36. Çakır M, Karaca İR Alveolar distraksiyon osteogenizi. GÜ Diş Hek Fak Derg 2012;29:121-8

37. Erverdi N, Küçükkeleş N, Şener C, Selamet BU. Interdental Distraction Osteogenesis for the Management of Alveolar Clefts: Archwise Distraction. Int J Oral Maxillofac Surg 2012;41:37-41.

38. Sunitha C, Gunaseelan R, Anusha V, Peruman K, Shanmugasundaram A. Maxillary Movement in Cleft Patients Treated With Internal Tooth Borne Distractor. J Maxillofac Oral Surg 2013;12:266-72.

39. Bousdras VA, Liyanage C, Mars M, Ayliffe PR. Segmental Maxillary Distraction with a Novel Device for Closure of a Wide Alveolar Cleft. Ann Maxillofac Surg 2014;4:60-3.

40. Aikawa T, Haraguchi S, Tanaka S, Uematsu S, Ishibashi M, Kogo $\mathrm{M}$, et al. Rotational movement of the anterior maxillary segment by hybrid distractor in patients with cleft lip and palate Oral Surg Oral Med Oral Pathol Oral Radiol Endod. 2010;110:291-300.

41. Karakasis D, Hadjipetrou L. Advancement of the anterior maxilla by distraction (case report). J Craniomaxillofac Surg 2004;32:150-4.

42. Kuroda S, Araki Y, Oya S, Mishima K, Sugahara T, TakanoYamamoto T. Maxillary distraction osteogenesis to treat maxillary hypoplasia: comparison of an internal and an external system. Am J Orthod Dentofacial Orthop 2005; 127:493-8.

43. Vega O, Perez D, Paramo V, Falcon J. A New Device for Alveolar Bone Transportation. Craniomaxillofac Trauma Reconstr. 2011;4:91106.

44. Constantino PD, Shyt G, Friedman CD, Pelzer HJ, Masini M, Shindo ML, et.al. Segmental mandibular regeneration by distraction osteogenesis. An experimental study. Arch Otolaryngol Head Neck Surg 1990;116:535-45.

45. Block MS, Brister GD. Use of distraction osteogenesis for maxillary advancement: preliminary results. J Oral Maxillofac Surg 1994;52:282-6.

46. Yen SL, Gross J, Wang P, Yamashita DD. Closure of a large alveolar cleft by bony transport of a posterior segment using orthodontic archwires attached to bone: report of a case. J Oral Maxillofac Surg 2001;59:688-91.

47. Tae KC, Gong SG, Min SK, Oh Whan S. Use of Distraction Osteogenesis in Cleft Palate Patients. Angle Orthod 2003;73:602-7.

48. Erverdi N, Motro M, Gozneli R, Küçükkeleş N.A Novel Vector Control Device in Horizontal Bone Transport. J Oral Maxillofac Surg 2013;71:768-74

49. Erverdi AN, Yilmaz B, Motro M, Gozneli R, Ugurlu K. Simultaneous alveolar cleft closure and dental midline correction with curvilinear intraoral distraction. Cleft Palate Craniofac J 2014;51:344-9.

\section{Alveolar distraction osteogenesis applications in cleft lip and palate patients: a literature review}

\section{Abstract}

Distraction osteogenesis technique has been successfully applied in the craniofacial area for long time, and it is being applied increasingly more in cleft lip and palate patients also. Especially in large cleft palate cases, bone grafting or surgical procedures such as distraction osteogenesis can be applied in order to ensure a smooth alveolar arc. In this literature review, alveolar (segmental) distraction osteogenesis applications in patients with cleft 
lip and palate, indications of the technique, advantages and disadvantages, application methods and types of appliances used for this purpose have been evaluated. As conclusion, especially with the application of alveolar (segmental) distraction osteogenesis, successful outcome can be achieved in cleft lip and palate patients with velopharyngeal insufficiency, maxillary hypoplasia and maxillary crowding, and this technique may be an alternative to conventional osteotomies and extraoral distractions.

KEYWORDS: Cleft lip; cleft palate; distraction osteogenesis; orthodontics 